\title{
Do artesanato intelectual ao contexto virtual: ferramentas metodológicas para a pesquisa social
}

TANIA STEREN DOS SANTOS*

\section{Resumo}

0 presente artigo examina os diversos procedimentos metodológicos, considerando especialmente as técnicas de pesquisa. São caracterizadas as mais tradicionais e também as novas estratégias utilizadas na pesquisa social no contexto da sociedade da informação. Salienta-se o impacto da incorporação das novas tecnologias da informática e da comunicação na pesquisa bibliográfica e documental e na pesquisa de campo. Ademais, é questionada a dicotomia das abordagens quantitativas e qualitativas, considerando sua complementaridade e interfaces. O paradigma da complexidade na perspectiva epistemológica apresenta avanços consideráveis, mas enquanto metodologia operativa está em seus primórdios. N esse sentido, o estudo trata do tema da triangulação, concebida como procedimento promissor na busca da perspectiva quanti-qualitativa. Diante do exposto, entende-se a tentativa de explorar um pouco mais as características dos procedimentos e recursos técnicos que podem ser utilizados pelos pesquisadores que procuram desenvolver projetos de pesquisa mistos.

Palavras-chave: Técnicas de pesquisa. Complexidade. Triangulação. Pesquisa quantitativa e qualitativa. Projetos de pesquisa mistos.

* Bacharelado e Licenciatura em Ciências Sociais pela U FRGS. M estrado no Programa de Pós Graduação em Sociologia da U FRGS. D outorado no Programa de Pós Graduação em Sociologia pela UFRGS. Professora do Departamento de Sociologia da U niversidade Federal do Rio Grande do Sul. 


\section{Iniciando com alguns antecedentes}

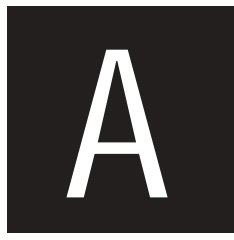

s técnicas tradicionais de coleta de dados, tais como, observações, questionários e entrevistas continuam sendo importantes ferramentas para a pesquisa empírica. As orientações de Wright Mills em Do artesanato intelectual $(1980)^{1}$ sobre estratégias de produção do conhecimento sociológico seguem tão vigentes quanto os ensinamentos de cunho epistemológico, teórico e metodológico na obra El ofício de sociólogo (BO URDIEU; CHAMBO RED O N ; PASSERO N, 1975). No entanto, novos recursos da informática e da comunicação nos colocam diante da necessidade de explorar adequadamente suas potencialidades, propiciando inovações nos procedimentos de investigação social.

A tendência atual na área da pesquisa social é de uma maior integração de textos, imagens e sons. Diante das aceleradas mudanças da sociedade da informação é necessário ter flexibilidade para a descoberta de formas diferentes de realizar o trabalho científico, incorporando as novas tecnologias desenvolvidas no mundo virtual, em especial, os recursos digitais e audiovisuais. Contudo, é oportuno refletir ainda sobre a sugestão de M ills de perseguir as virtudes do artesão intelectual, paciente e detalhista, evitando assim o "fetichismo do método e da técnica". o autor salienta a importância de relacionar os dados da pesquisa com sólidos conhecimentos epistemológicose referenciais teórico-conceituais substantivos.

Mills abordou na mencionada obra a questão da "inibição metodológica", criticando a exacerbação da visão quantitativista que consi-

1 Trata-se de um texto clássico no campo da metodologia, publicado na obra $A$ imaginação sociológica (1980). Nele o autor expõe detalhadamente como realiza cotidianamente seu trabalho de pesquisador. 
dera que tudo que não pode ser comprovado com dados numéricos se reduz a simples "filosofia social". Paul Lazarsfeld era o principal sociólogo a propor a transição das "filosofias sociais" para a sociologia "plenamente organizada", no sentido de ser avalizada pelo "M étodo Científico". Este objetivo somente poderia ser alcançado pela utilização de métodose técnicas de pesquisa quantitativa rigorosos.

Em contrapartida, M ills questionava o caráter superior e inconteste da proposta de Lazarsfeld de uma ciência objetiva, neutra e livre de juízos de valor, própria do referencial positivista. São oportunas as reflexões críticas de Moraes e Torres sobre o método positivista:

Acreditamos que as metodologias positivistas apresentam a limitação de refletir apenas instantes, momentos determinados, fragmentos da realidade, situações simplificadas e concretas vividas pelos sujeitos, sejam eles pesquisadores ou pesquisados. Ignora-se a riqueza dos processos vivenciados e os significados internos subjacentes aos comportamentosobserváveis. São como fotos instantâneas e estatizantes de processos que tentam nos mostrar que representamos a realidade como ela é, como um espelho na qual está refletida. E, hoje, sabemos que isto não é verdadeiro. Tais processos são dinâmicos e multidimensionais e todo e qualquer processo desta natureza está sujeito ao imprevisível, ao inesperado, ao acaso e ao criativo, e vão além do horizonte conhecido, revelando, assim, que toda identidade de um sistema complexo é sempre um processo de vir-aser. (MO RAES; TO RRES, 2009)2

Q uanto à questão do quantitativismo, em perspectiva histórica da sociologia latino-americana, Gino Germani, na Argentina, no final dosanos 1960, seguia postura semelhante à de Paul Lazarsfeld nos Estados U nidos.

2 Documento obtido na internet. 
De acordo com Blanco (2005, p. 36), Germani defendia a idéia de que as ciências sociais eram iguais às ciências naturais e que deveriam trabalhar com o mesmo padrão metodológico: "considerava que ao negar a possibilidade de aplicar métodos das ciências naturais à sociologia se favoreceu a especulação no lugar da pesquisa científica e que o conhecimento dos fenômenos sociais foi mais de caráter filosófico que científico ".

Nesta perspectiva observa-se a mesma preocupação de Durkheim em aplicar os cânones das ciências naturais ao conhecimento sociológico. Michael Löwy (1985) discorda desta posição e, ao comparar o positivismo e o historicismo, explica por que as ciências naturais e as ciências sociais são qualitativamente diferentes, tanto nos seus postulados quanto nos seus métodos.

No primeiro paradigma um pressuposto básico é que na natureza existem leis eternas, invariáveise independentes da vontade dos homense que a dinâmica social segue o mesmo cânone (os fatos sociais são "coisas" externas ao indivíduo e exercem poder de coerção sobre ele, na definição durkhemiana). No segundo paradigma, ao contrário, os fenômenos sociais são produto das ações do homem. Ademais, o "corpo social", a sociedade, funcionam de forma diferente do corpo humano e seu metabolismo e, portanto, as formas de conhecê-los seguem abordagens e procedimentos científicos qualitativamente diferentes (LÖ WY, 1985).

O sociólogo argentino Alfredo Poviña, primeiro presidente de ALAS Asociación Latinoamericana de Sociologia - em 1951, criticava tanto a postura da "sociologia ideológica" de orientação marxista - a chamada "sociologia comprometida" quanto a sociologia quantitativista da "fatologia", "quantofrenia" ou "técnica instrumentista puramente empiricista" (BLANCO, 2005, p. 41). Ao mesmo tempo, nesta perspectiva, a dimensão subjetiva era desconsiderada por ser "ideológica” em contraposição à explicação "científica" e "objetiva" da realidade social, de base positivista.

O s questionamentos de Bourdieu (1975), Thiollent (1980) e Löwy (1985) ao positivismo e ao empirismo na pesquisa social sedimentaram 
alguns postulados que serviram de orientação para o trabalho científico de inúmeros pesquisadores: a) a crítica à supremacia das ciências naturais sobre as ciências sociais; b) a inviabilidade da produção de um conhecimento sociológico sem nenhum tipo de interferência do sujeito sobre o objeto (pois toda observação é influenciada pelo ponto de vista do observador) e c) a consideração de que existem determinações epistemológicas e teóricas subjacentes à forma de estruturação das técnicas de coleta de dados.

A crítica e rejeição às técnicas quantitativas perduraram durante longo período, porém, nos últimos anos observa-se uma crescente valorização da capacidade de cálculo e precisão dos resultados provenientes da interligação das técnicas estatísticas com a microinformática. A estatística passou a ser atualmente uma ferramenta essencial que possibilita a otimização do conhecimento científico, produzindo dados com grande capacidade de generalização.

Sobre a questão da "neutralidade-objetividade da ciência" é preciso observar que na literatura sociológica estes dois conceitos sempre são tratados de forma interligada. Convém, todavia, reconhecer a necessidade de analisar separadamente cada conceito, concluindo que talvez o melhor caminho seja assumir a não-neutralidade e, mesmo assim, pretender a objetividade. Isto significa que o fato de adotar uma determinada concepção teórica e política, não implica necessariamente na renúncia à construção de conhecimentos objetivos em relação à realidade examinada (STEREN DOS SANTOS, 1991, p. 41). ${ }^{3}$

Nunca é demais referir que não existe uma pesquisa social totalmente objetiva e sem algum tipo de interferência do contexto e da subjetividade e que o papel do cientista social é o de tentar diminuir ao máximo as

3 Estas reflexões foram desenvolvidas em artigo que publicamos anteriormente denominado $D a$ neutralidade ao compromisso: a construção do conhecimento científico na pesquisa social, no qual confrontamos o método positivista e o histórico-estrutural, tecendo considerações sobre a relação sujeito-objeto do conhecimento, pesquisa participante, a questão da totalidade e das alternativas metodológicas (STEREN DOSSANTOS, 1991). 
distorções que possam surgir em cada etapa da investigação. Procedimentos científicos se tornam cada vez mais relevantes para a adequada apreensão do nosso objeto de pesquisa, pois representam a certificação de que o estudo segue padrões acadêmicos ad equados. ${ }^{4}$

A construção do objeto de pesquisa possibilita o afastamento do senso comum e a necessária interligação entre a epistemologia, a metodologia, a teoria e os dados empíricos, para que o conhecimento gerado não se limite à simples descrição empiricista de aspectos superficiais, fragmentadose parciais da realidade social.

\section{Pesquisa quantitativa ou qualitativa? Convergências, divergências e hibridações}

Ao escolher a metodologia de uma pesquisa uma indagação inicial é se meus dados representam magnitudes ou conceitos e categorias. Pretendo trabalhar com números, mensurando a realidade, ou com palavras, desenvolvendo uma abordagem mais voltada à compreensão do conteúdo? Apesar de que muito já se debateu e escreveu sobre a dicotomia da pesquisa quantitativa versus qualitativa, é necessário estabelecer algumas considerações a respeito, pois a questão não está ainda esgotada. A prática científica dos pesquisadores indica que grande parte costuma se alinhar a uma ou outra perspectiva, sem perceber a promissora possibilidade da união de ambas as estratégias metodológicas.

Não existe uma abordagem que trabalhe exclusivamente com técnicas estatísticas ou com depoimentos. Ambos os tipos de dados não são

4 Recomenda-se, especialmente, a leitura de duas obras publicadas em Buenos Aires por CLACSO - Consejo Latinoamericano de Ciencias Sociales, que oferecem importantes subsídiosnessa direção: Bibliotecas virtuales para las ciencias sociales (BABINI; FRAGA, 2004) e M anual de metodologia: construcción del marco teórico, formulación de los objetivosy elección de la metodologia (SAUTU et al, 2005). 
excludentes. A complexidade da vida em sociedade e o acelerado processo de transformação exigem atualmente a superação de posturas reducionistas em termos técnicos e operacionais.

Nos anos 1950 e 1960, quando ocorre considerável desenvolvimento da metodologia de pesquisa nas ciências sociais, existiam preconceitosquanto à utilização da estatística, principalmente entre os cientistas sociais de formação crítica. A busca da quantificação nos estudos sobre a sociedade esteve relacionada, durante longo tempo, ao paradigma positivista. Muitos pesquisadores tinham a visão de que somente adotando-se esta perspectiva seria possível aplicar métodos e técnicas rigorosos orientados à verificação empírica. As técnicas quantitativas eram identificadas com a sociologia norte-americana considerada, abstratamente, a serviço dos interesses dominantes. A estatística era vista com desconfiança e considerada como instrumento de manipulação e dominação. No entanto, salientou-se já a importância crescente das técnicas estatísticas na atualidade, decorrente do seu maior poder de generalização e precisão.

Ao trabalhar com técnicas quantitativas busca-se analisar o comportamento das variáveis individualmente ou na sua relação de associação ou de dependência com outras variáveis (quando há causalidade). São elaborados diversos gráficos ou tabelas de frequências univariadas (uma variável), com cruzamentos de duas variáveis (bivariadas) ou mais (multivariadas), no intuito de identificar características ou fatores explicativos dos fenômenos em estudo. O s dad os podem apresentar diferentes níveis de medição, possibilitando trabalhar com estatísticas descritivas ou inferenciais, com probabilidades, proporções ou correlações entre variáveis.

Entre os quantitativistas mais inflexíveis, grande parte dos estudos qualitativos é considerada como mera pesquisa "exploratória" ou "descritiva", com pouca capacidade de generalização. No entanto, quando neste tipo de pesquisa é adotado um elevado padrão científico, com utilização de técnicas de coleta de dad os adequadamente escolhidas e testadas, aliado à incorporação de teorias explicativas substantivas, pode-se diminuir a possi- 
bilidade da nossa pesquisa qualitativa ser caracterizada como "exploratória", comumente desqualificada pelos quantitativistas ${ }^{5}$.

Com o acelerado desenvolvimento das TICs(Tecnologias da Informática e da Comunicação) é possível realizar pesquisas qualitativas com maior rigor científico e capacidade explicativa. 0 que se perde em quantidade se ganha em profundidade. 0 s números e estatísticas podem não ser as ferramentas mais apropriadas para compreender ideologias e representações. O u seja, o tratamento matemático nem sempre é ad equado para pesquisas que têm como objetivo elucidar em profundidade motivações e ações. Ele é muito eficiente para traçar um perfil fidedigno de determinada população, caracterizando sua situação socioeconômica, pela utilização de técnicas de medida e controle de variáveis, mas quando se procura uma compreensão mais abrangente da estrutura discursiva dos atores sociais e seu comportamento, as técnicas qualitativas se tornam mais apropriadas. Pesquisas que utilizam este tipo de técnica estão demonstrando crescente poder de precisão nos seus procedimentos metodológicos.

As pesquisas realizadas mediante amostras representativas e com utilização de técnicas estatísticas têm, evidentemente, maior capacidade de generalização que as pesquisas qualitativas, onde as amostras passam a se denominar de "corpus", 6 mas não por isso os resultados podem ser considerados menos significativos e rigorosos.

5 Esta observação não diminui a importância dos estudos exploratórios, pois são fundamentais nas etapas iniciais de qualquer pesquisa social. Eles possibilitam uma melhor inserção do pesquisador na realidade empírica, ao adotar uma postura flexível nas suas primeiras observações. 0 contato informal e a observação do contexto propiciam o aperfeiçoamento das técnicas de coleta de dados, apreendendo aspectos relevantes insuspeitosno início do levantamento.

6 A expressão corpus é considerada mais adequada que amostra quando se trabalha em pesquisa qualitativa. Pode ser definida como: "coleção finita de materiais, determinada de antemão pelo analista, com (inevitável) arbitrariedade, e com a qual ele irá trabalhar" (BARTHES apud BAU ER; AARTS, 2004, p. 44). A caracterização de corpus como "escolha sistemática" ou "orientações para a seleção de informações" inclui materiaistextuais, sonorose visuais. No artigo da nossa autoria, elaborado conjuntamente com Brumer, Rosenfield e Holzmann (2008), denominado A elaboração de projeto de pesquisa em Ciências Sociais, são estabelecidas outras considerações a respeito desta questão. 
É importante salientar que entre os pesquisadores que trabalham com técnicas qualitativas ${ }^{7}$ também existe grande preocupação em tornar seus trabaIhos cientificamente confiáveis e a utilização de novas tecnologias, como por exemplo, as CAQ DAS (Computer-Aided Q ualitative Data Analysis Software) ${ }^{8}$ têm produzido avanços substanciais no campo metodológico nosúltimosanos.

O s pesquisadores que utilizam técnicas qualitativas adotam, principalmente, o paradigma fenomenológico ou compreensivista nas suas abordagens (embora técnicas qualitativas sejam utilizadas também por marxistas, pós-estruturalistas ou autores de outras escolas de pensamento). N os dois primeiros paradigmas são priorizadas as dimensões da ação e as interações intersubjetivas. N esse sentido, os fenômenos sociais são analisad os a partir da perspectiva subjetiva dos atores sociais envolvidos neles. Suas reflexões e representações são analisadas a partir das suas expressões discursivas. 0 conteúdo das narrativas é classificado em categorias de análise que permitem reconstruir a percepção sobre a realidade presente no discurso dos diferentes sujeitos, seus interesses, expectativas e ações.

O srelatos, depoimentose documentosinstitucionais, individuais ou de caráter biográfico, possibilitam compreender, ademais, o contexto histórico e sociopolítico no qual estão inseridos os sujeitos da pesquisa, considerando seu papel específico e as relações sociais das quais fazem parte. A análise do texto no contexto é fundamental para perceber seu sentido e significação.

7 Sobre pesquisa qualitativa o livro de Flick (2004) é uma referência na área, além da obra de Bauer e Gaskell (2004).

8 Tavares dos Santos, J. V. (coordenador do Dossiêsobre o tema Metodologiasinformacionaisna revista Sociologiasn. 5 (2001), escreveu um artigo denominado "As metodologias informacionais: um novo padrão de trabalho científico para as sociologias do século XXI?", no qual apresenta uma panorâmica sobre os avançosnesse campo. Especificamente sobre asCAQ DAS consultar, na revista Sociologiasn. 5, o artigo de Mangabeira, Lee e Fielding (2001) e o de Teixeira e Becker (2001). Na revista Sociologiasn. 9 foi também publicado um artigo de Cisneros (2003) sobre o assunto, no qual o autor expõe os passos a seguir no processo de codificação ("sistema de categorias temáticas") e na realização de análises comparativas de temas emergentes do discurso do entrevistado, em pesquisas qualitativas. 
A articulação de técnicas quantitativas e qualitativas numa mesma pesquisa é uma tendência atual da pesquisa social. Ao analisar a relação entre ambas as abordagens, Rodrigues (2007) salienta que elas têm muitos aspectos em comum:

O fator quantidade não exclui o fator qualidade. Assim é que o número 3, por exemplo, expressa uma quantidade e várias qualidades. Ser primo, ímpar, inteiro e positivo são algumas das qualidades do número 3. As quantidades expressam ainda algumasnão-qualidades. O mesmo número três não é par, não é fracionário, não é quadrado perfeito, não é negativo. O s aspectos citados são exemplos de qualidades intrínsecas às quantidades [... ] a pesquisa que se vale de números não está forçosamente excluída da condição de qualitativa, como dito, malgrado os rótulos largamente divulgados. Registre-se, ainda, que as pesquisas ditas quantitativas não se restringem ao âmbito dos estudos descritivos, ao contrário da falácia neste sentido, largamente divulgada. É clássica - além de elementar - a divisão da Estatística em descritiva e inferencial. A primeira compreende tabelas, gráficos, medidas de tendência central e de variabilidade, úteis à descrição. A Estatística inferencial utiliza largamente os testes de significância, os instrumentos de verificação da existência de correlações entre os fatos ou eventos, dentre outros instrumentos. (RODRIGUES, 2007, p. 35-36)

0 autor também distingue a lógica discursiva da lógica matemática, ambas com seus códigos específicos de comunicação e esclarece que: "o código gramatical, assim como o código matemático, é um conjunto de representações, por isso expressam idéias, com as quaisse elaboram proposiçõese raciocínios, quando associados, formando uma corrente de idéias" (Ibidem, 2007, p. 37).

O s delineamentos metodológicos modernamente incorporam diferentes técnicas de coleta e análise de dados, integrando múltiplas estratégias 
de pesquisa. Os fenômenos sociais apresentam diversas dimensões e interfaces e sua ad equada abordagem requer, com frequência, a integração de aspectos subjetivos com determinantes estruturais ou contextuais mais abrangentes. Desta forma, podem ser interligadas perspectivas macro e microsociais de forma complementar, assim como, incorporar procedimentos mistos nas etapas da coleta, processamento ou análise dos dados.

A combinação de diversas técnicas de pesquisa possibilita o desenvolvimento de pesquisassociaismais precisase interessantes. 0 desenho multimétodo, com a combinação de estratégias quali-quanti parece ser mais completo e efetivo do que os realizados exclusivamente com uma das duas abordagens.

\section{Das velhas às novas ferramentas na pesquisa social}

Dentre as técnicas de pesquisa que podemos considerar como tradicionaisencontram-se as seguintes: planilhas de observação, questionários, roteiros de entrevistas, fotografias, filmes, estatísticas oficiais e dados documentais. ${ }^{9}$

No trabalho doscientistas sociais o levantamento e revisão bibliográfica (dados secundários) são fundamentais nas etapas iniciais da pesquisa para mapear o "estado da questão" e estabelecer uma adequada delimitação do tema. A pesquisa documental ${ }^{10}$ (dados primários) é uma das técnicas mais

9 Apenas para distinguir tipos (gênero) de documentos, apresenta-se a seguinte classificação: material gráfico, fônico (discos em diversos formatos), audiovisual (filmes, fotografias, cartográfico (mapa, atlas), iconográfico (desenhos, gravuras, pinturas) e objetos de arte, folclore ou indumentárias. Entre os documentos gráficos ou textuais (manuscritos, datilografados ou impressos) encontram-se: documentos oficiais, documentos jurídicos ou coleções particulares: certidões de cartórios, registros gerais de nascimentos, casamentos, mortes, desquites, atas, regimentos, notas, panfletos, cartas, autobiografias, memórias, editais, despachos, ofícios, circulares, mensagens, memorandos etc.

10 Para um maior aprofundamento da técnica de pesquisa documental consultar o capítulo 8 do livro de Tim M ay (2004) denominado "Pesquisa documental: escavações e evidências e também 0 artigo de Lang (1999), D ocumentose depoimentos na pesquisa histórico-sociológica." 
antigas na história do pensamento humano, tendo atualmente importante desenvolvimento pela digitalização e ampliação do acesso on-line.

No caso da pesquisa bibliográfica e documental se coloca a necessidade de verificar se as fontes são confiáveis, eliminando o denominado "lixo cibernético". Sobre a autenticidade dos documentos, as questões colocadas por Tim May (2004) possibilitam conferir maior grau de cientificidade aos nossos estudos:

Os dados são genuínos? São de uma fonte primária ou secundária? São de fato o que parecem ser? São cópias autênticas dos originais? Foram corrompidos ou adulterados? A autoria pode ser validada? O s documentos estão datadose localizados? São registros precisos dos eventos ou processos descritos? O s autores dos documentos são dignos de crédito? (FO STER apud MAY, 2004, p. 220).

Dentre os vários tipos de documentos é interessante analisar a fotografia, pois se trata de um recurso que está sendo cada vez mais valorizado nas pesquisas acadêmicas, especialmente pela capacidade de registro e tratamento de imagens, decorrente da incorporação de novas tecnologias digitais. A análise dos dados visuais pode proporcionar uma série de informações importantes sobre o contexto, os acontecimentos, as características dos sujeitos de um determinado lugar, sua cultura ou habitusde classe, gênero, gerações ou etnias.

A título de exemplo, em uma pesquisa sobre as relações familiares na cidade de São Paulo, no início do século XX, a equipe utilizou a história oral e fotografias como principais técnicas de pesquisa. Foram entrevistadas pessoas idosas com o objetivo de elucidar o cotidiano da sua vida familiar, a relação pais-filhos e entre os parceiros, focalizando o tema do exercício da autoridade na família. A problemática da pesquisa estava centrada nas relações de gênero dentro e fora do espaço doméstico. No que se refere à utilização de fotografias, como técnica de construção do conhecimento sociológico, são relevantes as reflexões a seguir: 
Inicialmente pensou-se em utilizar a fotografia somente como técnica complementar, como forma de apoio, um meio de captação e reforço da memória dos idosos, mas a riqueza das fotos encontradas chamou a atenção das pesquisadoras para a importância de sua análise e interpretação numa pesquisa sociológica e, assim, se resolveu ampliar os objetivos desse trabalho, de modo que se pudesse dar maior ênfase à própria metodologia, associando a fotografia, como técnica de coleta de dados, aos depoimentos dos membros vivos das famílias da época. [...] Pelo fato do senso comum considerar a fotografia como 'prova', fazendo com que aquilo que nosparece duvidoso se torne certo a partir de sua presença e representando ela o grau máximo de proximidade ao modelo fotografado, aumenta a dificuldade em se divulgar a idéia contrária, isto é, a de que a fotografia seria uma visão parcial e particular do objeto fotografado, só podendo ser vista cientificamente como constituída também dessa forma. [...] Como criação do imaginário, as imagens fotográficas conseguem revelar formas de classificar e apreender, entre outras coisas, as relações sociais e as ideologias dos sujeitos que, de alguma forma, contribuíram para a sua produção. [...] À ciência sociológica não interessa analisar um documento frio, que retrata um momento único do passado, mas um registro inserido num contexto de tempo e espaço que 0 antecede e o vai suceder, além de conter também um contexto de ordem sócio-cultural implicitamente presente em toda fotografia. 0 registro fotográfico representa um fragmento da realidade social e a tarefa do pesquisador é ir além desse fragmento, isto é, situar esta visão parcial da realidade no contexto em que ela foi produzida e a partir dos interesses que norteiam o estudo. (CAM POS, 1999, p. 73; 76-77) 
A técnica fotográfica é muito apropriada para estudos sobre família, assim como a técnica de história de vida. Esta pode ser utilizada também para estudar, por exemplo, a temática da violência urbana ou rural, da migração ou dos moradores de rua, analisando trajetórias individuais ou coletivas, a partir de imagens registradas pelo próprio pesquisador, cedidas pelos entrevistad os ou coletadas em outras fontes impressas ou digitais.

Sobre a questão das fotografias como "reforço da memória" Loizos salienta que, ao realizar uma entrevista, é necessário estar preparado de antemão para desencadear lembranças nas pessoas entrevistadas, e ele apresenta exemplos de pesquisas sobre histórias de sindicatos ou de partidos políticos. 0 autor menciona também que uma fotografia de uma multidão, publicada em algum jornal, ao ser mostrada pode ativar lembranças sobre detalhes do acontecimento, sobre indivíduos participantes e suas motivações (LOIZOS, 2004, p. 143).

No processo de transição de métodos e técnicas tradicionais para novas formas de coleta e análise de dados, no contexto da sociedade informática, Mariño lembra a necessidade de se adotar "una posición epistemológica que no esté eclipsada ni por la fascinación tecnológica ni por un pesimismo tecnofóbico" (M ARIÑ O, 2008 ${ }^{11}$ ). Ambas as posturas extremas em relação à inovação tecnológica são prejudiciais, tanto a daqueles pesquisadores que incorporam acriticamente todas as novidades que se acumulam rapidamente quanto a dos que as rejeitam incondicionalmente.

Sobre o impacto das mudanças atuais na realidade virtual e na investigação, Galindo registra que na "cibersociedade" a utilização de instrumentos e ferramentas aumenta e isto cria um cenário favorável ao desenvolvimento da pesquisa científica, acrescentando que: "El espacio social se articula con más y mejores vínculos y conexiones. Las relaciones humanas se complejizan, el tiempo y el espacio de la vida se amplifican, más cosas 
suceden con más gente involucrada. Muchos perciben y se perciben, muchos interactúan, la información circula, se modifica, se critica, se analiza, se sintetiza" (GALINDO, 2009²).

Nesses novos espaços, surgem expressões originais no campo teórico-metodológico, além dos tradicionais conceitos de interdisciplinaridade ou multidisciplinaridade: ciências de fronteira, interciências, multimétodo, multimetodologia, dado complexo, complexidade, meta-análise, transmetodologia, práticas interparadigmáticas, bases interteóricas, multidimensionalidade, entre outras. Todos se referem a aspectos mais abrangentes da pesquisa, na qual não há lugar para a simplicidade e reducionismo na coleta, processamento e análise dos dados.

É necessária uma revisão das técnicas tradicionais de coleta de dados, incorporando os novos recursos disponíveis no espaço cibernético, especialmente aqueles que representam inovações no campo metodológico. Àstécnicas de pesquisa tradicionaise à linguagem textual se incorporam novas formas de registro da expressão humana, provenientes de diversas fontes, especialmente das novas mídias digitais (vídeo, televisão, cinema e internet). Com efeito, na pesquisa social são incorporados novos recursos audiovisuais: material sonoro e fílmico, em diversos formatos, provenientes do mundo virtual ou de locadoras, videotecas, cinematecas, museus ou centros de documentação.

Cabe lembrar que muitos dados audiovisuais são produzidos pelo próprio pesquisador. N este caso, entrevistas individuais ou grupais (grupo focal $^{13}$ ), assim como dados de observações, podem ser filmados de acordo

12 D ocumento obtido na internet.

13 A técnica de grupo focal pode ser definida como: "uma técnica de pesquisa que coleta dados por meio das interações grupais ao se discutir um tópico especial sugerido pelo pesquisador. Como técnica, ocupa uma posição intermediária entre a observação participante e as entrevistas em profundidade. Pode ser caracterizada também como um recurso para compreender o processo de construção das percepções, atitudes e representações sociais de grupos humanos" (GO NDIM , 2008). Documento obtido na internet. 
com os objetivos da pesquisa. O registro minucioso, por exemplo, da vida cotidiana, acontecimentos, processos de trabalho, costumes e peculiaridades dos diversos atores sociais são documentados com câmaras digitais, obtendo-se assim, informações importantes sobre a estrutura e dinâmica social. Recursos audiovisuais produzem, ademais, maior riqueza de dados nas pesquisas que utilizam as técnicas de reconstrução histórica, história de vida e história oral, como é o caso dos depoimentos de pessoas que ainda estão vivas e foram vítimas do H olocausto, no período nazista da Segunda Guerra M undial. ${ }^{14}$

A sociologia visual surge a partir da preocupação em integrar outras linguagens, além da textual, na forma de coletar dados, registrar e divulgar resultados de pesquisas. Da mesma forma que a técnica de história oral foi questionada no período do seu surgimento pela história tradicional, a sociologia visual (assim como a antropologia visual, que apresenta importante desenvolvimento no país nos últimos anos) tem enfrentado oposição dos cientistas sociais mais tradicionais. Estes questionam a cientificidade dos procedimentos audiovisuais pela possível falta de rigor científico e interferências produzidas pelo contexto e subjetividades.

É preciso ter em mente, no entanto, que as novas mídias e programas de informática, que integram imagens com textos e sons, têm propiciado maior qualidade e precisão metodológica às pesquisas científicas. As redes eletrônicas de informação no espaço "cibernético" têm modificado as formas de realizar o trabalho científico e divulgar os resultados. ${ }^{15}$ Assim, os novos recursos tecnológicos operam mudanças substanciais nas formas de definir e delimitar as amostras, na formatação e aplicação das técnicas de

14 Sobre a técnica de história oral é muito elucidativo o artigo de Camargo (1978), pesquisadora do CPDO C, Centro de Pesquisa e D ocumentação de História, da Fundação Getúlio Vargas no Rio de Janeiro. Também estão disponíveis on-line grande quantidade de depoimentosno site da instituição: http://www.cpdoc.fgv.br/comum/htm/index.htm

15 Para uma leitura de questões atuais sobre a sociedade da informação é interessante a obra organizada por M aíra Baumgarten Conhecimento e redes. sociedade, política e inovação (2005), publicada com apoio de ALAS - Asociación Latinoamericana de Sociología. 
coleta de dados e no processamento, assim como, nas ferramentas de análise, que se tornam cada vez mais sofisticadas.

Todas as inovações tecnológicas têm contribuído substancialmente para a melhor qualificação das pesquisas sociais. Em contrapartida, parece estar ocorrendo um aspecto negativo no mundo virtual com a facilidade de acesso a textos originais: a ampliação das diversas formas de plágio, pela utilização indevida de informações. ${ }^{16}$

No novo contexto virtual, a área de Biblioteconomia se transformou em Ciência da Informação, tornando-se um campo do conhecimento indispensável para o trabalho científico. As bases de dados são sistematizadas e colocadas à disposição dospesquisadores, de forma cada vez mais eficiente e produtiva.

O s mecanismos de busca se sofisticaram e o acesso à informação tornou-se um direito inquestionável dos cidadãos. A utilização de filtros facilita as buscas, possibilitando a identificação das referências mais significativas e a melhor delimitação do tema da pesquisa. Como exemplo, os operadores booleanos and, or e not, entre outros recursos, são ferramentas disponíveis para restringir ou aumentar a nossa pesquisa bibliográfica e documental.

Entre os principais sites para a realização de levantamentos e compilação pode-se mencionar: Portal de Periódicos da CAPES - www . periodicos .capes.gov.br; SCIENTIFIC ELECTRO NIC LIBRARY O N LINE - www . scielo .org; SCIENCEDIRECT - www.sciencedirect.com; SCOPUS- www . scopus .com; ISI WEB OF KNOWLEDGE/ WEB OF SCIENCE - www. scientific. thomson.com. Registrando-se neste último site é possível ter acesso ao

16 Há, entretanto, softwares capazes de identificar o plágio em textos acadêmicos, inclusive apontando quantitativamente o grau de cópia presente em determinado texto e indicando a localização das fontes originais nos diversos sites da internet. Consultar, por exemplo, o seguinte endereço, onde é possível baixar o programa denominado Farejadordeplagio gratuitamente para realizar uma varredura de trechos plagiados em 50\% do texto: http://br.geocities.com/ farejadordeplagio/. Algumas universidades, em diversos países, já estão começando a exigir dos alunos que eles mesmos realizem e imprimam a certificação de autenticidade da autoria, a qual deverá ser entregue junto com o trabalho a ser avaliado. 
programa EndN ote, o qual possibilita organizar e compartilhar referências. Ele armazena até 10.000 referências na nossa base de dados pessoais à qual se pode ter acesso pela internet. Ele insere referências e formata documentos automaticamente e também muda instantaneamente o sistema de norma técnica de acordo com nosso interesse em adaptar o texto ao formato exigido por determinado país ou publicação.

Nestas plataformas também se podem criar diversostipos de ALERTS(de busca, de assunto, de volume/edição e de citação) para sermosnotificados por correio eletrônico, caso sejam incluídas novas informações no sistema (escoIhe-se notificações mensais, semanais ou diárias). Isto significa que se for registrado em alguma base de dados um novo artigo sobre um tema que estamos pesquisando ou se um autor da nossa preferência publicou resultados de uma nova pesquisa, estaremos recebendo uma mensagem de aviso.

O utro aspecto importante para a realização de pesquisas sociaisé que se observa atualmente um acesso mais irrestrito a sites de instituições públicas e privadas, grupos sociais ou indivíduos com informações mais transparentes sobre as suas características e interesses. 0 s atores sociais, individuais e coletivos divulgam material diversificado que pode ser utilizado como fonte de pesquisa (mensagens eletrônicas, documentos, listas, cadastros, informativos on-line etc. ). Bases de dad os confiáveis oferecem cada vez maior quantidade de informações, assim como páginas eletrônicas de sitesna internetespecializados em temáticas específicas, centros ou núcleos de pesquisa e blogs nacionais e internacionais. O s diversos sites, portanto, se constituem em valiosas fontes de informações para pesquisas, possibilitando o acesso mais rápido a documentos, assim como, a divulgação e disponibilização de publicações científicas.

Entre os aspectos positivos, a internet tem propiciado maior interação entre pesquisadores que utilizam os diversos recursos disponibilizad os pela tecnologia digital, de forma individual ou através de reuniões virtuais. A 
construção de plataformas para a colaboração remota on-line cria um espaço virtual de interação e trabalho conjunto no qual um projeto de pesquisa é postado e os participantes arquivam e disponibilizam, via internet, grande quantidade de dados textuais e multimídia para pesquisas. A rede também facilita a organização de equipes de trabalho, situadas em contextos diferentes. Surgem trabalhos compartilhados entre pesquisadores com múltiplas e descentralizadas perspectivas. Nesse sentido, a internet, está tendo impacto considerável na implementação de estudos comparativos entre países, regiões ou localidades, tanto de forma sincrônica quanto diacrônica.

É cada vez mais frequente a coleta de opiniões e depoimentos pela internet. Ao elaborarmos nossos próprios instrumentos de coleta de dadosa serem aplicados on-line, (questionários ou formulários, roteiros de entrevistas, pauta de observação, conversas ou discussões eletrônicas etc.) podemos ter uma maior proximidade com os informantes, estabelecendo processos interativos de comunicação. A propósito, uma câmara digital instalada no computador também permite um contato sujeito-objeto da pesquisa mais próximo, ou seja, a observação e o diálogo com a pessoa que responde.

É interessante observar, ademais, que são criados atualmente sites específicos para a coleta de dados de determinada pesquisa, com informações detalhadas sobre os objetivos do estudo. Assim, procura-se ter um maior número de pessoas dispostas a responder às indagações formuladas pelos pesquisadores. N este caso, é importante que o instrumento de coleta de dados apresente um cabeçalho explicativo sobre o estudo que seja suficientemente esclarecedor como para que os sujeitos da pesquisa colaborem, tendo o cuidado, no entanto, de não influenciar as suas respostas.

As enquetes eletrônicas autorespondidas por indivíduos ou agentes coletivos, que possuem endereço eletrônico ou sites, podem ser uma forma muito produtiva de coletar dados, com baixo investimento em termos de tempo e recursos financeiros. Hair et al (2005) comparam as "surveys 
por e-mail" e as "surveys pela internet", considerando que as primeiras são mais popularese de menor custo. Entretanto, destacam que as realizadas pela internet são mais flexíveis e que as taxas de resposta parecem ser mais elevadas pela maior garantia de anonimato dos participantes. O sautores explicam que:

$O$ acesso às surveys mantidas na WEB é controlado por senhas para garantir que somente os respondentes qualificados respondam os questionários de acordo com instruções específicas. O sindivíduos são contatados e solicitados a participar, recebendo, então, uma senha personalizada. Assim como nas surveys por email, as surveys pela internet são rápidas e oferecem dados de alta qualidade. Mas são mais caras devido aoscustos de programação de sites na Web (HAIR et al, 2005, p. 162).

As videoconferências, as trocas de informações em tempo real, os grupos de debates, as comunidades, os sites de relacionamento, as redes de sociabilidade e todo tipo de site que possibilita aos usuários postar mensagens podem ser utilizados como fonte de dados para pesquisas sociais. É importante lembrar que quando se trata de pesquisas anônimas é mais difícil recorrer a estes meios e que nas pesquisas virtuais é necessário definir o tipo de amostragem e o perfil dos informantes que seja mais ad equado ao objeto da pesquisa.

O utra questão relevante é a invasão de privacidade de indivíduos ou instituições. Nas ciências sociais, assim como ocorre nas ciências da saúde, é frequente que o pesquisador, ao realizar entrevistas, assine conjuntamente com o entrevistado o Termo de Consentimento Livre e Esclarecido ou o também denominado Consentimento Informado. ${ }^{17}$ Este instrumento propicia uma mútua garantia de respeito a princípios éticos durante todo o processo da pesquisa e, principalmente, na apresentação dos resultados. 0

17 Trata-se de um documento no qual o entrevistado concorda com a divulgação dos seus depoimentose informações, geralmente com garantia de anonimato. 
objetivo é evitar a divulgação de informações que possam estar distorcidas ou conter erros de interpretação, preservando, sempre que possível, o anonimato daquelas pessoas ou entidades que tenham respondido às indagações da pesquisa.

As técnicas modernas de formatar questionários para coletar respostas on-line, podem, aos poucos, vir a substituir os procedimentos da pesquisa tradicional. A comunicação presencial parece, não obstante, a melhor forma de coleta de dados, pois o diálogo direto é um importante instrumento de avaliação da adequação das respostas às perguntas formuladas e da postura do informante.

$\mathrm{N}$ a etapa de processamento e análise de dados o domínio de programas especializados na pesquisa social, como, por exemplo, o SPSS, NVivo ou SPHIN $X^{18}$, entre outros, tornaram-se insubstituíveis recursos, contribuindo para o aperfeiçoamento do conhecimento científico da realidade social.

Por outro lado, cumpre registrar que a comunicação com pessoas que não dispõe de equipamentos informáticos impõe a necessidade de utilizar as técnicas convencionais de coleta de dados. A aplicação de instrumentos de pesquisa através de um entrevistador ou telefone, assim como autorespondidos de forma presencial, via correio ou fax, ainda são ferramentas necessárias, dado o número ainda expressivo de excluídos da era digital na nossa sociedade. As características da população-alvo determinam a escolha das técnicas mais ad equadas a cada situação.

18 Algumas informações sobre estes programas: SPSS: Statistical Package for the Social Science (Estados U nidos), um dos programas mais completos que existem atualmente para análise estatística de dados; o NVivo (Austrália), é um dos programas que oferece mais recursos para análise qualitativa de dados, dentre as denominadas CAQ DAS (Computer-Aided Q ualitative Data Analysis Software). Destaca-se a sua capacidade de integrar textos, imagense sons (formatos multimídia). 0 programa SPHINX (França possibilita a realização de coleta e análise de dados quantitativos e qualitativose possui importantes recursos para elaboração, formatação e aplicação de questionários on-line. 
Complexidade, triangulação e métodos mistos: multiplicidade de olhares sobre o objeto de pesquisa

N esta parte serão apresentadas algumas estratégias mais pluralistas de pesquisa, focalizando procedimentos e metodologias operativas que possibilitem a superação da tradicional dicotomia quanti/qualitativa.

$\mathrm{N}$ a era da sociedade da informação, surge a necessidade de explorarse mais profundamente 0 tema da complexidade, da triangulação e dos métodos mistos, como promissores caminhos de abordagem de desenvolvimento de pesquisas sociais.

Enfoquemosa princípio o método da complexidade proposto por M orin:

O método da complexidade pede para pensarmosnos conceitos, sem nunca dá-los por concluídos, para quebrarmos as esferas, para restabelecermos as articulações entre o que foi separado, para tentarmos compreender a multidimensionalidade, para pensarmosna singularidade com a localidade, com a temporalidade, para nunca esquecermos as totalidades integradoras [... ]. A totalidade é, ao mesmo tempo, verdade e não verdade, e a complexidade é isso: a junção de conceitos que lutam entre si. (MORIN , 2000, p. 192)

A seguir são apresentadas algumas considerações holísticas de Manuel A. Jorge (2006) sobre ciência e complexidade, em perspectiva holística: "As ciências teriam, agora, oportunidade de se redimirem dosprejuízose dasilusões da sua estratégia reducionista, analítica, quantitativa e estática perante uma natureza que não merecia tanta indiferença. Graçasà complexidade, seria possível recuperar a unidade perdida dos saberes, único modo de conhecer e de compreender uma realidade que se mutila se se dividir" (JO RGE, 2006, p. 24).

Ao analisar o paradigma dominante na ciência moderna Maíra Baumgarten aborda a fragmentação do conhecimento em compartimentos 
disciplinares e especializações e questiona sua adaptação às características da sociedade atual. ${ }^{19}$

[... natureza e sociedade nunca deixaram de ser complexas e o mundo atual é a expressão desta complexidade - os problemas que se nos apresentam são multidimensionais e as contradições se avolumam. 0 ser humano - alienado por suas próprias mãos - da natureza (que não deixa por isso de integrar) passou a ameaçá-la de forma perigosa para sua própria espécie e todas as outras. Vivemos um processo de hibridação entre o natural, o humano e 0 artificial. (BAU M GARTEN, 2006, p. 23)

O conceito de complexidade, no pensamento de Morin, parece ter sua origem no método histórico-estrutural e na dialética, no qual o concreto pensado é a síntese das múltiplas determinações e também pode ser relacionado ao conceito de totalidade. Ele permite a apreensão da estrutura, suas determinações e processo de transformação dos fenômenos sociais. 0 conhecimento da totalidade não significa abarcar todos os seus elementos constitutivos, implica sim em reconhecer que qualquer elemento singular tem um referencial explicativo numa dinâmica complexa e global.

Para compreender a realidade é necessário utilizar o recurso analítico, separando suas partes componentes para depois reconstituir o todo. As teorias da complexidade de Morin (1996) nos ensinam que o todo é mais do que a soma das partes e que para apreender sua estrutura e processo é necessário recorrer a procedimentos interativos e dinâmicos. Para tornar mais explícita a questão, a seguir são apresentadas algumas reflexões do autor sobre as partes e 0 todo no estudo da complexidade:

O que foi tecido junto; de fato há complexidade quando elementos diferentes são inseparáveis constitutivosdo todo

19 Na revista Sociologiasno 15 foi publicado um Dossiê coordenado por Baumgarten e Lima (2006) sobre esta temática. 
(como o econômico, o político, o sociológico, o psicológico, o afetivo, o mitológico) e há um tecido interdependente, interativo e inter-retroativo entre o objeto do conhecimento e seu contexto, as partes e o todo, e das partes entre si. Por isso, a complexidade é a união entre a unidade e a multiplicidade. (M O RIN , 1999-2000, p. 38)

Em termos operacionais, seguindo o paradigma da complexidade, Vasconcelos (2007) apresenta um tipo de variável que, no seu entender, não se enquadra nas classificações tradicionais: variáveis multidimensionais complexas. 0 autor assinala a multiplicidade de aspectos envolvidos e propõe que se trabalhe com índices:

Particularmente em ciências humanas, sociais e da saúde, existem processosmultidimensionais complexos, de características predominantemente qualitativas, masque também apresentam dimensões e facetas quantitativas. Algumas instituições reconhecidas de pesquisa e planejamento vêm propondo metodologias de conceituação e síntese avaliativa operacional dessas variáveis, exprimindo-as na forma de índices numéricos, visando Ihes dar visibilidade e comparabilidade em avaliações. São exemplos disso o Índice de Desenvolvimento Humano (IDH), do Programa das Nações Unidas para o Desenvolvimento Humano (PNUD), e o Índice de Condições de Vida, proposto pela Fundação João Pinheiro, de Belo Horizonte. (VASCO NCELOS, 2007, p. 236)

Esse entendimento, predominantemente técnico, sugere a necessidade de partir de uma rigorosa definição teórico-conceitual e proceder à desagregação das diferentes dimensões que compõem os conceitos principais. Desta forma, é possível formular as características dos indicadores e índices capazes de representar a complexidade da vida social.

A triangulação também promove o diálogo entre as diversas estratégias de pesquisa e áreas do conhecimento científico, objetivando uma análise 
cruzada dos procedimentos e resultados. 0 conceito de triangulação surge na área da topografia e consiste num recurso efetivo para analisar as intersecções, os vários pontos de vista sobre uma determinada problemática. U ma visão mais abrangente do tema em estudo e das várias perspectivas teórico-metodológicas disponíveis possibilita expandir a compreensão do objeto de pesquisa ou avaliar resultados provenientes da utilização de diferentes técnicas de coleta de dados.

Existem diversos tipos de triangulação que podem ser realizados no sentido de obter uma maior confiabilidade dos dadose ampliação de perspectiva: entre áreas do conhecimento científico (interdisciplinaridade); entre pesquisadores especialistas de diversos campos profissionais (situados em regiões diferentes dentro de um mesmo país ou em nível internacional); entre teorias, visando maior nível explicativo dos dados da pesquisa e também triangulação de técnicas, com o objetivo de integrar num mesmo objeto de pesquisa várias estratégias operacionais.

Considerando a relevância da triangulação, Denzin e Lincoln (2006) relacionam este conceito ao de pesquisa quantitativa e qualitativa e explicam de que forma são integradas ambas as técnicas:

Após a conclusão das entrevistas, a triangulação vem à tona como um elemento crítico na prática da ciência social: 'acrescentando' uma camada de dados à outra para construir um edifício confirmatório. Na análise quantitativa dos dados, a triangulação ocorre quando múltiplos itens dentro da mesma escala medem o mesmo constructo ${ }^{20}$, ou quando duas escalas diferen-

20 Constructo ou construto é definido por M artinse Theóphilo (2007, p. 35) da seguinte forma: "Para explorar empiricamente um conceito teórico, o pesquisador precisa traduzir a assertiva genérica do conceito em uma relação com o mundo real, baseada em variáveis e fenômenos observáveis e mensuráveis, ou seja, elaborar (construir) um constructo ou construto e operacionalizá-lo. Para tanto, necessita identificar as variáveis observáveis/mensuráveis que podem representar as contrapartidas das variáveis teóricas". 
tes unem-se para medir o mesmo constructo. Na pesquisa psicológica, especificamente, e às vezes na pesquisa sociológica, a tendência é empregar métodos qualitativos para suplementar os dados quantitativos. (DENZIN ; LINCO LN, 2006, p. 127)

A triangulação de técnicas de pesquisa é um procedimento que possibilita a ampliação de perspectivas. Pode-se integrar, por exemplo, num mesmo estudo a pesquisa documental, dados estatísticos, coletados via questionário, e incluir, concomitantemente, a análise de conteúdo de depoimentos colhidos através de entrevistas. Desta forma, a multiplicidade de técnicas pode propiciar um conhecimento mais aprofundado do objeto de pesquisa e um grau maior de cientificidade.

Independentemente de que o método escolhido para determinada pesquisa seja positivista, estruturalista, fenomenológico, materialista-dialético (histórico-estrutural), subjetivo-compreensivista, pós-estruturalista ou siga o paradigma da complexidade, podemos incorporar tanto técnicas quantitativas quanto qualitativas ou ambas as estratégias num mesmo estudo. As técnicas a serem justapostas, no qual cada uma representa formas diferentes de operacionalizar o objeto de pesquisa, podem atuar de forma complementar. É importante destacar, entretanto, que a triangulação de paradigmas ou métod os de abordagem não parece ser uma estratégia adequada, pois as experiências ecletistas demonstram que o conhecimento gerado pode ser uma confusa "colcha de retalhos". Da mesma forma, Vasconcelos questiona o ecletismo pelo "uso simultâneo, linear e indiscriminado de teorias e pontos de vista teóricos e éticos diversos sem considerar as diferenças e incompatibilidades de origem histórica, na base conceitual e epistemológica, e nas implicações éticas, ideológicas e políticas de cada um desses pontos de vista" (VASCO N CELOS, 2007, p. 108).

A partir desse entendimento indaga-se: como juntar pressupostos do paradigma positivista e marxista numa mesma pesquisa, por exemplo? Aqui 
vale recordar que seus conceitos fundamentais são diametralmente opostos. É possível integrar os conceitos de harmonia, integração e equilíbrio, próprios do referencial positivista com os de contradição e antagonismo, princípios básicos da dialética materialista?

É necessário salientar que o conhecimento das várias linhas de pensamento e perspectivas metodológicas da sociologia contribui para o aprimoramento da capacidade analítica e competência científica dos pesquisadores, contudo, questiona-se aqui a integração caótica de pressupostosirreconciliáveis. Isto não significa alinhamento incondicional a uma única perspectiva, pois como bem nos ensina Mills, é importante que o pesquisador raciocine "em termos de váriospontos de vista" para assim possibilitar que a sua mente "se transforme num prisma móvel, colhendo luz de tantos ângulos quanto possível" (MILLS, 1980, p.230). Além disso, é importante levar em consideração "a complexidade e multidimensionalidade dosfenômenosfísicos, biológicos, humanos, sociais e ambientais, que exigem um conjunto pluralista de perspectivas diferentes de abordagem" (VASCO NCELO S, 2007, p. 108).

Com efeito, a crescente complexidade da vida social exige uma sólida formação epistemológica e teórica dos pesquisadorese a implementação de estratégias de pesquisa múltiplas. É necessário conceber a realidade social como um processo objetivo-subjetivo, como uma totalidade, algo próximo da denominada complexidade multidimensional.

Por outro lado, a preocupação em desenvolver métodos mistos está cada vez mais presente no meio acadêmico na atualidade. Sua emergência se situa entre os anos 1960 e 1980, ocorrendo importante expansão a partir dos anos 1990. John Creswell informa que sua origem se deu "quando Campbell e Fiske usaram métodos múltiplos para estudar a validade das características psicológicas. Eles encorajaram outros a empregar seu 'modelo multimétodo' para examinar técnicas múltiplas de coleta de dados em um estudo". (CRESWELL, 2007, p. 32).

Nos projetos de pesquisa mistosé estabelecida uma junção de procedimentosquantitativose qualitativos numa mesma pesquisa. O sdados quan- 
titativos são combinados com os dad os qualitativos provenientes de observações, entrevistas ou outro tipo de fonte. D esta forma, busca-se comparar diferentes facetas da realidade para ter uma melhor compreensão das características e fatores constituintes de determinado fenômeno social.

Nos projetos de métodos mistos a integração de dados numéricos e de dados textuais ou audiovisuais num mesmo estudo pode ser desenvolvida de forma simultânea/concomitante ou em sequência (CRESW ELL, 2007, p. 218-219), ou seja, os dados quanti-quali são coletados no mesmo período de realização da pesquisa de campo ou trabalha-se inicialmente com uma etapa e, depois de concluída, inicia-se a próxima. Para trabalhar com esta abordagem Creswell sugere as seguintes orientações práticas:

- Transformação de dados: nas estratégias concomitantes ${ }^{21}$, o pesquisador pode quantificar os dados qualitativos. Isso envolve criar códigos e temas qualitativamente; depois contar o número de vezes que eles ocorrem nos dados de texto[...]. Essa quantificação de dados qualitativos permite ao pesquisador comparar resultados quantitativos com dados qualitativos. Alternativamente, o investigador pode transformar dados quantitativos em qualitativos [...].

- Explorar casos discrepantes: em um modelo seqüencial, uma análise de dados quantitativos na primeira fase pode gerar casos extremos ou discrepantes. Fazer entrevistas qualitativas de acompanhamento com esses casos discrepantes pode resultar em informações sobre a razão pela qual eles divergiram da amostragem quantitativa.

- Desenvolvimento de instrumento: em uma técnica seqüencial, obtenha temas e declarações específicas

21 Creswell (2007) utiliza a expressão de "modelo aninhado concomitante" e explica que ele "pode ser identificado pelo uso de coleta de dados em uma fase, durante a qual tanto dados quantitativos como qualitativos são coletados simultaneamente" (CRESW ELL, 2007, p. 220). 
dosparticipantes em uma coleta inicial de dados qualitativos. Na próxima fase, use essas declarações como itens específicos e como temas para escalas com o fim de criar um instrumento de pesquisa que seja baseado na visão dos participantes. U ma terceira fase final pode ser a validação do instrumento com uma grande amostra representativa da população.

- Examine níveis múltiplos: em um modelo aninhado concomitante, conduza um estudo em um nível (por exemplo, com famílias) para obter resultados quantitativos sobre uma amostra. Ao mesmo tempo, colete entrevistas qualitativas (por exemplo, com pessoas) para explorar o fenômeno com membros específicos das famílias. (CRESW ELL, 2007, p. 223)

Na avaliação de Vasconcelos (2007), em sua obra Complexidade e pesquisa interdisciplinar: epistemologia e metodologia operativa existe uma carência de formulações operacionais concretas em estudos com essa abordagem e afirma que os manuais de pesquisa existentes não estão atualizados ou, em geral trabalham com "uma concepção mais convencional e homogênea de conhecimento científico". o autor acrescenta que "por sua vez, os debates mais recentes sobre a crise dos paradigmas científicos- pós-modernismo, complexidade, interdisciplinaridade, etc. - ainda não produziram sistematizações mais operativas no plano metodológico (VASCO N CELOS, 2007, p. 7).

Da mesma forma, Creswell salienta que o conhecimento sobre a integração de métodos quantitativos e qualitativos em projetos de métodos mistos ainda não está suficientemente desenvolvido: "Há pouca coisa escrita até agora para orientar o pesquisador nesse processo. Além disso, há poucos conselhos sobre como o pesquisador pode resolver discrepâncias que ocorram entre os dois tipos de dados" (CRESWELL, 2007, p.221). No entanto, o autor apresenta algumas pistas importantes nessa direção, ao propor uma lista de perguntas para que os pesquisadores se coloquem a si mesmos ao trabalharem com métodos mistos: 
Q uadro 1. Lista de verificação de questões para elaborar um procedimento de métodos mistos

- Foi providenciada uma definição básica de pesquisa de métodos mistos?

- O leitor tem uma concepção do uso do potencial de uma estratégia de métodos mistos?

- Foram identificados os critérios para escolha de uma estratégia de métodos mistos?

- A estratégia foi identificada e foram mencionados os critérios de seleção?

- Foi apresentado um modelo visual que ilustre a estratégia de pesquisa?

- Foi usada uma notação apropriada para apresentar um modelo visual?

- Foram mencionados os procedimentos para coleta e análise de dados e sua relação com o modelo?

- Foram mencionadas as estratégias de amostragem para coleta de dados quantitativos e qualitativos? Elas estão relacionadas com a estratégia?

- Foram indicados procedimentos específicos de análise de dados? Eles estão relacionados com a estratégia?

- Os procedimentos para validar dados quantitativos e qualitativos foram discutidos? - A estrutura narrativa foi mencionada? Ela está relacionada ao tipo de estratégia de métodos mistos que está sendo usado?

Fonte: John Creswell (2007, p. 212)

Todas as perguntas aqui indicadas desafiam os pesquisad ores na construção de novas alternativas de pesquisa. Diante do exposto entende-se a necessidade de observar adequadamente os critérios na escolha de estratégias mistas, definindo um determinado modelo e estabelecendo sua relação com os procedimentos adotados. A definição da amostra quantitativa e do corpusqualitativo, a coleta de dados, os procedimentos de validação, a mensuração e análise dos dados quantitativos, assim como, da estrutura narrativa, exigem um detalhamento de estratégias centradas nas peculiaridades do objeto de pesquisa.

Partindo do delineamento da pesquisa, que envolve a elaboração de um plano geral de coleta e operacionalização dos dados, selecionam-se os métodos e técnicas a serem utilizados e as formas de aplicação. A estratégia multimetodológica possibilita integrar a técnica de observação com a de entrevista e questionário, entre outras. A sobreposição de procedimentos permite analisar a problemática em estudo a partir de diversos ângulos e dimensões.

A seguir indicam-se alguns proced imentos, de forma comparativa, em três metodologias de pesquisa, salientando que o método misto representa uma proposta de conciliação das estratégias qualitativas e quantitativas: 
Sociologias, Porto Alegre, ano 11, no 21, jan./jun. 2009, p. 120-156

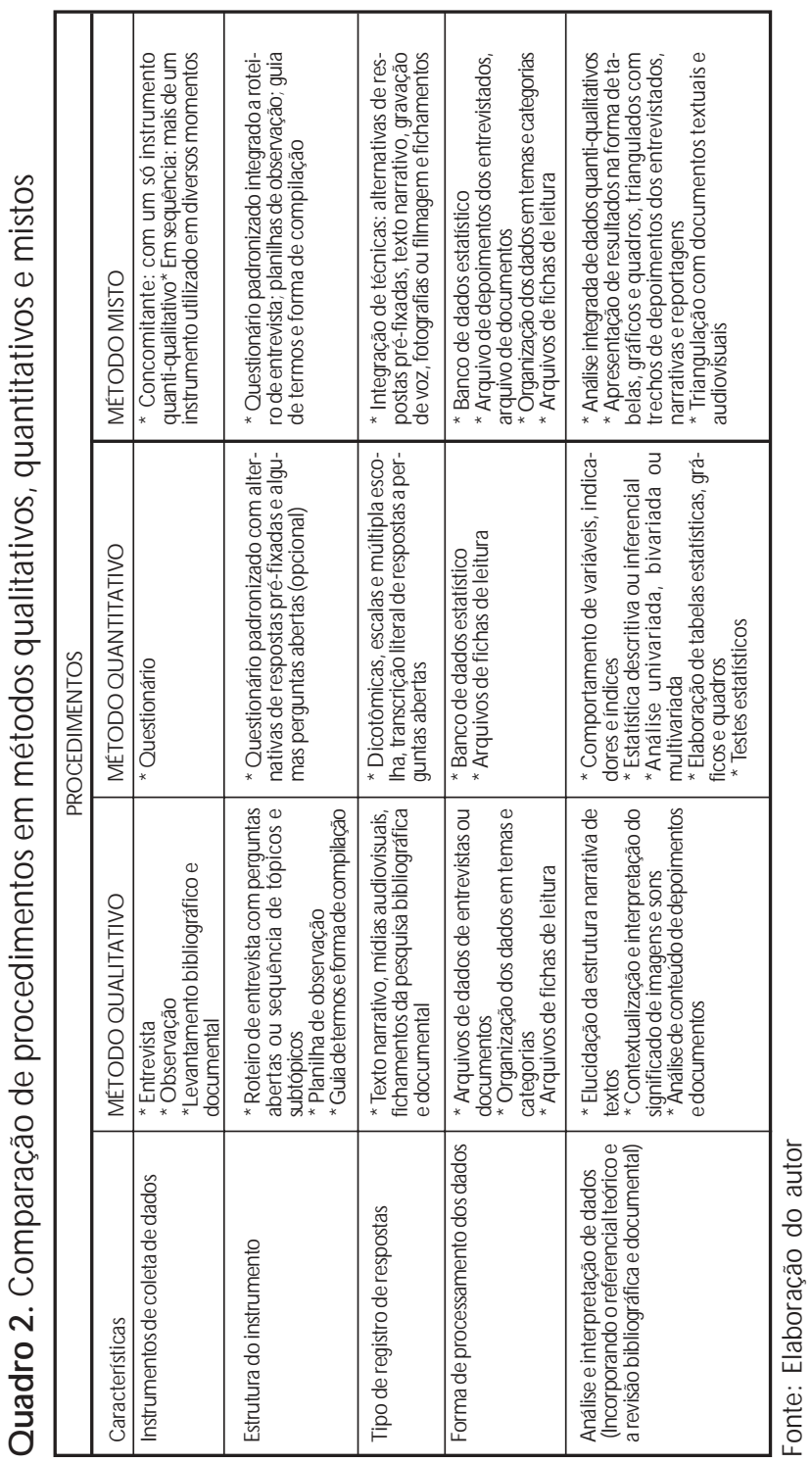


Cumpre registrar que todos os procedimentos podem ser desenvolvidos em ambientes virtuais ou presenciais, sendo necessário avaliar os aspectos positivos ou negativos das estratégias escolhidas em cada situação concreta.

No método misto, a interligação de diversas informações que podem ser comparadas, permite uma maior abertura da perspectiva da investigação e o aprofundamento da análise dos dados. A complementariedade dos procedimentos cria condições mais favoráveis à superação de eventuais distorções e erros durante todo o processo da pesquisa. Diante das várias opções metodológicas coloca-se a questão da fidedignidade e validação dos dados, diretamente relacionada com a qualidade da pesquisa. ${ }^{22}$

Como avanços no campo metodológico observam-se, na atualidade, a tendência à utilização de múltiplas fontes de evidências, uma maior transparência a respeito da natureza dos dados, assim como a explicitação das estratégias de pesquisa adotadas. Disso decorre uma situação mais favorável para avaliar se os resultados se adequam aos requisitos de cientificidade esperados.

\section{Considerações finais}

O bserva-se atualmente no campo científico uma ampliação das interações entre pesquisadores e informantes e a construção de uma dimensão mais coletiva do conhecimento. As novastecnologias da informática e da comunicação, em especial a internet, estão gerando padrões de comunicação mais participativos e dialógicos, com importantes impactos no

22 U m instrumento de medição é confiável, seguro ou fidedigno quando, aplicado repetidamente a um mesmo indivíduo ou grupo, ou ao mesmo tempo por pesquisadores diferentes, proporciona resultados iguais ou parecidos. A fidedignidade diz respeito à autenticidade das fontes. A validade refere-se à formulação de hipótesese adequação dos instrumentos de coleta e análise de dados, de modo a atingir os objetivos propostose obter-se uma representação da realidade o mais próximo possível do real. U ma mensuração é válida quando mede de alguma maneira demonstrável aquilo que trata de medir, livre de distorções sistemáticas (ANDER-EGG, 1995). 
trabalho dos cientistas sociais. Foi mencionada também a maior facilidade de acesso às fontes e dados para pesquisas e a ampliação do processo de difusão científica que ocorre na atualidade.

Embora na pesquisa social ainda sejam utilizadas técnicas tradicionais de coleta de dados (observação, questionários e entrevistas), a valorização de estratégias de investigação que incorporam recursos inovadores disponíveis no mundo virtual é cada vez maior. Mudanças nas técnicas de registro, armazenamento e divulgação de informações estão ampliando e modificando substancialmente o trabalho dospesquisadores.

$\mathrm{N}$ a coleta de dados são utilizadas as técnicas de observação e/ou entrevistas, com a crescente incorporação de modernos recursos audiovisuais e digitais. N ovas textualidades e representações simbólicas em ambientes digitais alteram profundamente as formas de perceber e analisar o mundo social. As representações e concepções dos sujeitos sobre sua realidade, expectativas e práticas se materializam nas suas expressões orais, textuais e corporais e novas tecnologias apresentam importante capacidade de registro e análise.

0 recurso da triangulação e o desenvolvimento de projetos de pesquisa de método misto se apresentam como ferramentas operacionais importantes, considerando a necessidade de inovação das técnicas tradicionais de coleta, processamento e análise de dados.

O embate entre os pesquisadores alinhados a técnicas qualitativas ou quantitativas foi intenso e ainda perdura, embora a tendência mais atual seja no sentido de ampliação do reconhecimento mútuo e integração entre ambas as abordagens.

A cientificidade da pesquisa em ciências sociais tende a um maior nível de aperfeiçoamento pela utilização de diversas técnicas de pesquisas de forma integrada num mesmo estudo. Certamente esta é uma forma mais efetiva de apreensão da realidade, numa sociedade cada vez mais complexa.

N esse contexto, é necessário considerar um aspecto essencial para a realização de estudos com maior poder explicativo, nas dimensões teóricas 
e metodológicas: a incorporação de uma problemática crítica e a análise das suas conexões com a totalidade. Cabe ainda assinalar a relevância de estabelecer uma adequada vinculação das técnicas de pesquisa com os pressupostos conceituais que as determinam. Estas questões centrais, apreendidas na época do artesanato intelectual, mantém sua necessária atualidade nos novos ambientes virtuais da pesquisa social.

\section{From intellectual craft to the virtual context: methodological tools for social research}

\section{Abstract}

This article examines different methodological procedures, and especially the research techniques. It characterizes both the traditional and the new strategies of social research that are used within the context of the information society. The author emphasizes the impact of incorporating the new computing and communication technologies in the bibliographic and documental research, as well as the field research. Furthermore, the article questions the dichotomy of quantitative and qualitative approaches, considering its complementarity and interfaces. The paradigm of complexity in the epistemological perspective shows considerable progress, but as an operating methodology it is still in its initial stages. In this sense, the study addresses the issue of triangulation, designed as a promising procedure in the search for the quantitative-qualitative approach. Considering the arguments, the author intends to explore further into the characteristics of the procedures and technical resources that can be used by researchers seeking to develop joint research projects.

Keywords: Research techniques. Complexity. Triangulation. Q uantitative and qualitative research. Joint research projects.

\section{Referências}

ANDER-EGG, Ezequiel. Técnicas de investigación social. Buenos Aires: Lúmen, 1995. 
BABINI, Dominique; FRAGA, Jorge. Bibliotecas virtuales para las ciencias sociales. Buenos Aires: CLACSO, 2004.

BAUER, Martin W.; GASKELL, George (Orgs). Pesquisa qualitativa com texto, imagem e som: um manual prático. Petrópolis: Vozes, 2004.

BAUER, Martin W.; AARTS, Bas. A construção do corpus: um princípio para a coleta de dados qualitativos. In: BAU ER, Martin W.; GASKELL, George (O rg). Pesquisa qualitativa com texto, imagem e som: um manual prático. Petrópolis: Vozes, 2004. p. 39-63.

BAU M GARTEN, Maíra. Conhecimento e redes: sociedade, política e inovação. Porto Alegre: Editora da UFRGS, 2005.

. Sociedade e conhecimento: ordem, caos e complexidade. SO CIO LO GIAS, Complexidade, Porto Alegre, Programa de Pó-Graduação em Sociologia, ano 8, n.15, p 16-23, jan-jun. 2006.

BLAN CO, Alejandro, La Asociación Latinoamericana de Sociología: una historia de sus primeros congresos. SO CIO LO GIAS, Porto Alegre, ano 7, no 14, p. 22-49, jul-dez 2005.

BO U RD IEU, Pierre; CH AM BO RED O N, Jean-Claude; PASSERO N, Jean-Claude. El ofício de sociólogo. Buenos Aires: Siglo XXI, 1975.

BRU MER, Anita; RO SEN FIELD, Cinara L.; HOLZM AN N, Lorena; SANTO S, Tania Steren dos. A elaboração de projeto de pesquisa em Ciências Sociais. In: PINTO, Celi R. J.; GUAZZELLI, Cesar A.B. (O rg) Ciências Humanas: pesquisa e método. Porto Alegre: Editora da UFRGS, 2008. p. 125-146.

CAM ARGO , Aspácia A. 0 ator, o pesquisador e a história: impasses metodológicos na implantação do CPDOC. In: NUNES, Edson de Oliveira $(0 \mathrm{rg})$ A aventura sociológica: objetividade, paixão, improviso e método na pesquisa social. Rio de Janeiro: Zahar, 1978. p. 276-304.

CAMPOS, Maria Cristina S. de S. A associação da fotografia aos relatos orais na reconstrução histórico-sociológica da memória familiar. In: LANG, Alice B. da S. G (O rg). Reflexões sobre a pesquisa sociológica. São Paulo: CERU, 1999. p. 73-86.

CISNERO S PUEBLA, César A. Análisis cualitativo asistido por computadora. SO CIO LO GIAS, M etodologias informacionais, Porto Alegre, Programa de Pó-Graduação em Sociologia, ano 5, n.9, p. 288-313, jan-jun. 2003.

CRESW ELL, John W. Projeto de pesquisa: método qualitativo, quantitativo e misto. Porto Alegre: Artmed, 2007.

DENZIN, N orman K; LINCO LN, Yvonna S. 0 planejamento da pesquisa qualitativa: teorias e abordagens. Porto Alegre: Artmed, 2006. 
FERNÁNDEZ-MO LINA, Juan Carlos. Derecho de autor y bibliotecas digitales: en busca del equilibrio entre intereses contrapuestos. TRANSINFO RMAÇÃO, Campinas, v. 20, n 2, p. 123-131, mai-ago 2008.

FLICK, U we. Uma introdução à pesquisa qualitativa. Porto Alegre: Bookman, 2004. GALINDO , Cáceres Luis Jesús. Cibercultura en la investigación: intersubjetividad y producción de conocimiento, Revista Textos de la CiberSociedad, 3. Temática Variada. Disponível em: http://www.cibersociedad.net. Acesso em: 14 jan. 2009. GO LDIM , José Roberto. Aspectos éticos relacionados à autoria científica. D isponível em: http://www.propesq.ufrgs.br/ . Acesso em: 12 dez. 2005.

GO NDIM, Sônia Maria Guedes. Grupos focais como técnica de investigação qualitativa: desafios metodológicos. Disponível em: www.usp.br/paideia/artigos/ 24/03.doc. Acesso em: 10 nov. 2008.

H AIR Jr., Joseph F. et al Fundamentos de métodos de pesquisa em administração. Porto Alegre: Bookman, 2005.

JORGE, Maria M anuel Araújo. O impacto epistemológico das investigações sobre a complexidade. In: Sociedade e conhecimento: ordem, caos e complexidade. SO CIO LO GIAS, Complexidade, Porto Alegre, Programa de Pó-Graduação em Sociologia, ano 8, n.15, p 16-23, jan-jun 2006.

LANG, Alice B. da S. G. Documentos e depoimentos na pesquisa histórico-sociológica. In: LAN G, Alice B. da S. G (O rg). Reflexões sobre a pesquisa sociológica. São Paulo: CERU, 1999. p. 59-72.

LANGE, Deise F. 0 impacto da tecnologia digital sobre o direito de autor e conexos. São Leopoldo: Editora da UNISINOS,1996.

LOIZOS, Peter. Vídeo, filme e fotografias como documentos de pesquisa. In:

BAUER, Martin W.; GASKELL, George (O rg) Pesquisa qualitativa com texto, ímagem e som: um manual prático. Petrópolis: Vozes, 2004. p. 137-155.

LÖ WY, M ichel. Ideologias e ciência social: elementos para uma análise marxista. São Paulo: Cortez, 1985.

MANGABEIRA, Wilma C.; LEE, Raymond M.; FIELDING, Nigel G. Padrões de adoção, modos de uso e representações sobre tecnologia: usuários do CAQDAS no Reino Unido, em meados da década de 90. SO CIO LOGIAS, Metodologias informacionais, Porto Alegre, Programa de Pó-Graduação em Sociologia, ano 3, n. 5, p. 20-57, jan-jun 2001.

MARIÑO, Miguel Vicente. Nuevas tecnologías, nuevas oportunidades metodológicas: revisando el papel del diseño metodológico y de las técnicas de investigación en las ciencias sociales contemporáneas. Disponível em: http:// ww w. ciberso ciedad. net/congres2006/gts/comunicacio. php?llengua $=$ es $\& \mathrm{id}=948$. Acesso em: 15 out. 2008. 
MARTINS, Gilberto de Andrade; THEÓ PHILO, Carlos Renato. Metodologia da investigação científica para ciências sociais aplicadas. São Paulo: Atlas, 2007.

M AY, Tim. Pesquisa social: questões, métodose processos. Porto Alegre: Artmed, 2004. M ILLS, C. W right. A imaginação sociológica. Rio de Janeiro: Zahar, 1980.

MORAES, Maria C.; DE LA TORRE, S. Pesquisando a partir do pensamento complexo: elementos para uma metodologia de desenvolvimento eco-sistêmico. Disponível em: http://revistaseletronicas.pucrs.br/ojs/index.php/faced/article/ viewFile/440/336. Acesso em: 3 jan. 2009.

M O RIN, Edgar. 0 problema epistemológico da complexidade. M ira-Sintra - M em Martins, Ed. Europa-América, 1996.

. Os sete saberes necessários à educação do futuro. São Paulo: Cortez; ŪNESCO, 1999/2000.

. Ciência com conciência. Rio de Janeiro: Bertrand Brasil, 2000.

RODRIGUES, Rui Martinho. Pesquisa acadêmica: como facilitar o processo de preparação de suas etapas. São Paulo: Atlas, 2007.

SO CIO LO GIAS. Complexidade. Porto Alegre: Programa de Pós-Graduação em Sociologia, ano 8, n.15, jan-jun 2006.

SAUTU, Ruth et al Manual de metodología: construcción del marco teórico, formulación de objetivos y elección de la metodología. Buenos Aires: CLACSO , 2005.

STEREN DOS SANTOS, Tania. Da neutralidade ao compromisso: a construção do conhecimento científico na pesquisa social. Cadernos de Sociologia, M etodologias de pesquisa, Porto Alegre, v.3, n.3, p. 33-53, 1991.

TAVARES DOS SANTOS, José Vicente. As metodologias informacionais: um novo padrão de trabalho científico para as sociologias do século XXI? SO CIO LO GIAS, M etodologias informacionais, Porto Alegre, Programa de Pós-Graduação em Sociologia, ano 3, n.5, p. 16-19, jan-jun. 2001.

TEIXEIRA, Alex N.; BECKER, Fernando. N ovas possibilidades da pesquisa qualitativa via sistemas CAQ DAS. SO CIO LO GIAS, M etodologias informacionais, Porto Alegre, Programa de Pó-Graduação em Sociologia, ano 3, n.5, p. 94-112, jan-jun 2001.

THIO LLENT, M ichel. Crítica metodológica, investigação social e enquete operária. São Paulo: Polis, 1980.

VASCO NCELOS, Eduardo Mourão. Complexidade e pesquisa interdisciplinar: epistemologia e metodologia operativa. Petrópolis, RJ: Vozes, 2007.

Recebido: $27 / 01 / 2009$ 